Published in final edited form as:

Clin Liver Dis. 2017 February ; 21(1): 103-113. doi:10.1016/j.cld.2016.08.008.

\title{
Drug Hepatotoxicity:
}

Environmental Factors

Jonathan G. Stine, MD, MSc ${ }^{a}$ and Naga P. Chalasani, MD ${ }^{b,{ }^{*}}$

aDivision of Gastroenterology \& Hepatology, Department of Medicine, University of Virginia, 1215

Lee Street, PO Box 800708, MSB 2145, Charlottesville, VA 22908, USA

bDivision of Gastroenterology and Hepatology, Department of Medicine, Indiana University School

of Medicine, 702 Rotary Building, Suite 225, Indianapolis, IN 46202, USA

\section{Keywords}

Drug-induced liver injury; Liver toxicity; Cirrhosis; Acute liver failure; Alcohol; Smoking

\section{INTRODUCTION}

It is estimated that more than 1100 drugs or herbal agents are associated with DILI. ${ }^{1}$ DILI can present as various forms of both acute and chronic liver disease and, although selflimited in the majority of cases, can have more severe consequences, with approximately a $10 \%$ case fatality or transplantation rate within the first 6 months of DILI onset and a $20 \%$ rate of progression to chronic liver injury. ${ }^{2-8}$ DILI remains the leading cause of acute liver failure (ALF) both in the United States and internationally. ${ }^{1-3,5,9,10}$ Geographic variation is common in the most frequently implicated agents ${ }^{1,9,11}$ for a variety of reasons, including host and environmental factors, such as xcessive alcohol and tobacco consumption, infection, pro-inflammatory states, and variations in circadian rhythm. Although host factors are much more robustly described across the body of literature, the environment promoting hepatotoxicity is an ever-expanding and in some instances unexplored field. Environmental factors are important considerations for both intrinsic, or dose-dependent DILI, and idiosyncratic DILI (iDILI). Intrinsic DILI, although more rare, occurs in individuals at the same toxic dose threshold. ${ }^{12,13}$ iDILI remains more problematic, less understood, and much more dependent on both environmental and genetic covariates to produce a milieu of susceptibility at the individual level. Currently available testing to both predict and diagnose iDILI in premarketing and postmarketing trials is largely ineffective ${ }^{14}$ and most cases of iDILI are discovered when medications are prescribed in much greater volume after regulatory approval. ${ }^{15}$ This review focuses on the available evidence supporting specific environmental factors (Box 1) and their influence on the likelihood and outcomes of DILI.

*Corresponding author. nchalasa@iu.edu.

Disclosure: Dr N.P. Chalasani serves as a consultant to many pharmaceutical companies for both nonalcoholic steatohepatitis and drug hepatotoxicity, but none of them represents significant and direct conflict with this review article. Dr J.G. Stine has nothing to disclose. 


\section{GEOGRAPHIC VARIATION}

The World Health Organization (WHO) initially began the Programme for International Drug Monitoring (PDIM) in 1968 involving 10 countries, a majority of which were in the regions of Europe or North America (including the United States), in a collaborative effort to pool national data from spontaneous adverse event reporting systems. ${ }^{16}$ Ultimately, this collaboration led to the creation of VigiBase in the mid-1990s, a database system comprised of more than 7 million individual case safety reports that became accessible for medical research in 2012 and publically searchable in a limited fashion in 2015 (http:// www.vigisearch.org). ${ }^{16}$ This collaboration has expanded to more than 80 nations and currently includes the regions of Africa, Asia, and Latin America. ${ }^{16}$

In an analysis of VigiBase that spanned data from 2000 to 2009 , Agaard and colleagues ${ }^{17}$ found geographic variation in both frequency of adverse drug reaction (ADR) reporting as well as the type of medication associated with the ADR. Low-income countries, as defined by the World Bank, were less likely to report ADRs. ${ }^{17}$ Low-income countries reported a greater frequency of ADRs with antibiotics and antifungal and antiviral medications whereas ADRs were more common for immunomodulatory and antineoplastic drugs in high-income nations. ${ }^{17}$ The investigators postulated that ADR reporting was more a feature of income rather than actual geography and highlighted the need to improve ADR reporting rates in low-income nations, in particular African nations that contribute less than $1 \%$ of the total individual case safety report volume. ${ }^{18}$ Despite this, several important differences between African nations and all other countries in the WHO-PDIM are worth noting. African nations report DILI occurring on average in a younger population (18-44 years of age) compared with 45 to 64 years of age in the rest of the world, and $28 \%$ of all ADRs reported were attributable to antiviral medications used to treat HIV. ${ }^{18}$ Further highlighting geographic differences in DILI, an analysis of VigiBase by Suzuki and colleagues, ${ }^{19}$ limited to the United States, England, and Sweden, found that of the 385 unique medications reported, only $9.7 \%$ appeared in all 3 registries. Of the 47 drugs subjected to regulatory action, only 6 were found in all 3 regions. ${ }^{19}$ Reports from European centers were also more homogenous compared with reports from the United States. ${ }^{19}$ A recent report from a single center in India that does not perform liver transplantation incorporating 303 cases of hepatotoxicity from 1997 to 2008 found that $58 \%$ were attributable to tuberculosis agents ${ }^{10}$; strikingly, no cases of APAP toxicity were reported. Despite this, a $17.3 \%$ case-fatality rate was reported, owing largely to ALF from anti-TB drugs. ${ }^{10}$

\section{EXCESSIVE ALCOHOL CONSUMPTION}

Although excessive alcohol consumption has historically been incorporated into causality assessment, namely that put forth by the Council for International Organizations of Medical Sciences, ${ }^{12}$ only a handful of medications have been demonstrated to have increased hepatotoxic potential in the setting of excessive alcohol use, namely APAP, highly active antiretroviral therapy (HAART), halothane, and anti-TB therapy with isoniazid or methotrexate. ${ }^{12}$ 
Coined alcohol-APAP syndrome ( $A A S$ ), the risk of APAP toxicity in the setting of alcohol use has been well described since the $1980 \mathrm{~s} .{ }^{20-24}$ AAS is related to CYP2E1 induction as well as glutathione depletion directly attributable to the toxic effects of alcohol. ${ }^{22}$ Concurrent malnutrition can predispose a patient to liver injury in this setting through impaired glucuronidation. ${ }^{22,25,26}$

The chronicity of consumption of alcohol may also a role in hepatotoxicity. In a series of 645 patients with singe-dose APAP toxicity, Schmidt and colleagues ${ }^{20}$ found that chronic alcohol abuse was an independent predictor for mortality while controlling for other confounding factors (odds ratio [OR] 3.52; 95\% CI, 1.78-6.97), including renal failure, which has previously been implicated in the increased mortality in this patient population. ${ }^{27}$ When APAP overdose superimposed on chronic alcohol consumption (defined as $>21$ drinks per week for men and $>14$ drinks per week for women) presents with acute renal failure with creatinine greater than $3.0 \mathrm{mg} / \mathrm{dL}$, prothrombin time greater than 100 seconds, and grades III-IV portosystemic encephalopathy, the prognosis is uniformly fatal. ${ }^{27}$ In a prospective nested case-control study of 150 patients with anti-TB drugs, associated DILI drawn from an overall cohort of 3900 patients exposed to anti-TB drugs, Gaude and colleagues ${ }^{28}$ found that $42.2 \%$ of DILI cases had significant chronic alcohol consumption and that alcohol abuse was predictive of DILI risk on adjusted multivariable analysis.

On the other hand, acute alcohol ingestion may be protective against hepatotoxicity. In animal models, acute alcohol ingestion inhibits CYP2E1 oxidation of APAP, ultimately resulting in a lower level of $N$-acetyl-p-benzoquinone imine, the reactive metabolite responsible for the known hepatotoxic potential. ${ }^{29}$ This has been corroborated in human observational study because acute ingestion of alcohol in alcoholic patients was associated with a profound reduction in risk (OR $0.08 ; 95 \% \mathrm{CI}, 0.01-0.66$ ) of APAP hepatotoxicity. ${ }^{20}$

Alcohol is also thought to play a role in hepatotoxicity attributed to HAART when used for the treatment of HIV (namely protease inhibitors and non-nucleoside reverse transcriptase inhibitors).$^{30}$ Excessive alcohol use may also lead to decreased treatment efficacy and acceleration of HIV to AIDS through changes in CYP2E1 and CYP3A4 activity. ${ }^{31}$ This is important to recognize given that approximately one-fourth of patients with newly diagnosed HIV are alcohol dependent. ${ }^{30}$ With the widespread use of similar classes of medications to treat chronic hepatitis $\mathrm{C}$ virus (HCV) as a part of the new all-oral direct-acting antiviral regimens and the overlap with comorbid polysubstance abuse, including alcohol, it will be interesting to see if alcohol consumption with the direct-acting antivirals predisposes to either hepatotoxicity or loss of treatment effect, because reports of the hepatotoxic potential of these medications have already surfaced. ${ }^{32}$ There have been several reports of increased hepatotoxicity with HAART in patients with HIV/HCV coinfection who abuse alcohol. ${ }^{33,34}$

Alcohol abuse in heavy quantities is associated with accelerated fibrosis in patients who are prescribed chronic immunosuppressive therapy with the antimetabolite methotrexate. ${ }^{35,36} \mathrm{In}$ a meta-analysis of 15 studies, including 636 patients, Whiting-O'Keefe and colleagues ${ }^{36}$ found the pooled risk of advanced fibrosis was $17.8 \%$ versus $4.5 \%(P=.003)$ in heavy drinkers, which was defined as greater than or equal to $100 \mathrm{~g}$ of alcohol per week. This population also had histologic progression more frequently (73\% vs $26 \%, P=.002) .{ }^{36} \mathrm{In}$ 
accordance with expert opinion, pretreatment liver biopsy is often considered on an individual basis in patients with a history of heavy alcohol consumption to assess for advanced fibrosis prior to initiation of methotrexate.

Despite the evidence put forth from the aforementioned studies, several large registries have not validated the risk of excessive alcohol consumption and any association with DILI. 5,11,37 A majority of patients in a Spanish registry of 461 subjects with DILI had alcohol consumption less than $40 \mathrm{~g} / \mathrm{d}$.

\section{SMOKING}

In contrast to the available body of evidence for excessive alcohol and its role in hepatotoxicity development, the literature describing tobacco smoking is much less prevalent and is based solely on observational studies. A Brazilian series of 131 subjects treated with anti-TB drugs found a decreased risk of developing anti-TB DILI in active smokers compared with lifelong nonsmokers (OR 0.28; 95 CI, 0.11-0.64; $P<.01$ ). ${ }^{38}$ Additionally, the investigators found that CYP2E1, despite known to be induced by smoking, was not associated with hepatotoxicity, confirming previous reports. ${ }^{39,40}$ CYP1A2 may also be up-regulated by smoking without known clinically relevant hepaotoxicity. ${ }^{40} \mathrm{~A}$ single-center experience in Denmark of 602 patients with APAP toxicity found that $70 \%$ were daily tobacco users and this was predictive of severity of injury (diagnosed by significantly higher peak aminotransferase and international normalized ratio levels) as well as all-cause mortality (OR 3.64; 95\% CI, 1.23-10.75). ${ }^{41}$ On the other hand, Wada and colleagues $^{42}$ found that, of the 33 patients in a series of 123 patients with prostate cancer treated with the antiandrogenic drug flutamide, which is metabolized by both CYP1A2 and CYP3A enzymes, smoking was associated with significantly lower odds of hepatotoxicity.

\section{INFECTION AND INFLAMMATION}

Infection and inflammation, through innate immune responses to the invasion of the body by foreign agents, including bacteria, viruses, and fungus, may predispose a patient to either intrinsic DILI or iDILI. The risk of intrinsic, or dose-dependent, DILI is due largely to a left shift in the dose-response curve, thereby sensitizing hepatocytes to injury, ${ }^{43-45}$ through a complex proinflammatory cascade involving pathogen-associated molecular patterns, damage-associated molecular patterns, Toll-like receptors, Kupffer cells, tumor necrosis factor (TNF)- $a$, natural killer cells, interferon gamma, polymorphonuclear neutrophils, endothelial cells, prostaglandins, dendritic and stellate cells, and both the coagulation ${ }^{46}$ and complement systems, the specifics of which are beyond the scope of this review but have been described in detail by other investigators. ${ }^{13}$

Animal models using both lipopolysaccharide (LPS) and TNF- $a$ exposed mice have found that these models of inflammation predispose to intrinsic DILI from both APAP and trovafloxacin. ${ }^{43,45}$ The timing of LPS administration varied in hepatotoxicity risk in APAP animal models, where LPS given 2 hours before APAP had significantly greater risk compared with LPS administration 24 hours prior to APAP. ${ }^{47}$ Animal models investigating the exogenous stress of cocaine administration have found that LPS augments the injury 
from cocaine. ${ }^{48}$ Because both TNF- $a$ and LPS are surrogates for circulating endotoxemia, it is surprising that advanced fibrosis and cirrhosis have not been ${ }^{49}$ documented to significantly increase the risk of DILI for a large number of medications; however, most medications have not been largely studied in patients with cirrhosis and dose adjustment for cirrhosis is often lacking in the prescribing information, despite changes in both pharmacokinetics and pharmacodynamics in this special population. ${ }^{49}$

Inflammation and infection also seem to play a greater role in iDILI and ultimately hepatic necrosis. Similar to intrinsic DILI, a majority of evidence is afforded from animal models. In the setting of LPS-induced endotoxemia, various medications, such as amiodarone, diclofenac, halothane, ranitidine, sulindac, and trovafloxacin, have been implicated in iDILI. 13,44,50-53 Proinflammatory TNF- $a$ also plays a role in iDILI because blocking TNF- $a$ with pentoxifylline in several of these animal models proved effective in decreasing the severity of liver injury. ${ }^{44,50}$ The coagulation system is also activated in periods of acute inflammation and the balance between procoagulation and anticoagulation shifts toward thrombotic risk. LPS administration in animal models has led to increased levels of circulating plasminogen activator inhibitor 1 (PAI-1) and ultimately increased fibrin deposition in experimentally induced iDILI. ${ }^{54}$ PAI-1 may also play a role in the mechanism of intrinsic DILI form $\mathrm{APAP}^{46}$ and has been implicated in other inflammatory processes in the liver (namely nonalcoholic steatohepatitis). ${ }^{55}$ Furthermore, anticoagulation with heparin-reduced fibrin deposition and thrombin generation has been shown to lead to an attenuation of the hepatotoxic response, ${ }^{54}$ and treatment with tissue plasminogen activator (streptokinase) has been shown to reduce hepatotoxicity through a similar mechanism. ${ }^{56}$ Collectively, these animal models suggest that activation of the coagulation cascade leads to fibrin deposition and ultimately tissue hypoxia and worsening cellular death and necrosis, findings that warrant validation in human models where to date, the majority of serum testing has focused on drug-induced ALF and the role of microparticles. ${ }^{57}$ These membrane fragments of 0.1 $\mu \mathrm{m}$ to $1.0 \mu \mathrm{m}$ are derived from systemic inflammation and seem predictive of worse clinical outcomes in ALF, including those cases that are drug-induced.

\section{CIRCADIAN RHYTHM AND THE HEPATIC CLOCK}

Circadian time is an important process affecting both the pharmacokinetic as well as the pharmacodynamic properties of drugs across a 24 -hour span. ${ }^{58}$ This so-called hepatic clock is driven by the central suprachiasmatic nucleus of the hypothalamus, which organizes the majority of circadian change at the cellular level. ${ }^{59}$ Fasting-feeding cycles in association with rest-activity rhythms help synchronize the hepatic clock, including the control of xenobiotic detoxification, in effect allowing for the temporal coordination of metabolism. 59,60

Although the available data are mostly from animal models investigating anti-TB medications and APAP, ${ }^{58,61-66}$ there have been extensions in the human population. ${ }^{67}$ Through lipid peroxidation inducing mitochondrial toxicity, Souayed and colleagues ${ }^{58}$ found that toxic doses of isoniazid in mice at 1 and 9 zeitgeber time produced severe hepatic necrosis whereas dosing at 17 zeitgeber time did not. Deletion of circadian gene Per1 has 
been shown to change the hepatotoxic risk from alcohol, ${ }^{62}$ whereas mPer2 has a role in the diurnal variation of APAP toxicity, both in mice. ${ }^{64}$

Patients taking APAP may also be predisposed due to hepatotoxicity due to 24-hour circadian variation. ${ }^{59,68}$ This may be due in part to the normal pattern of intermittent fasting states over a 24 -hour period because during times of fasting, ${ }^{68}$ glutathione levels are known to drop, ${ }^{69,70}$ thus potentially decreasing a protective mechanism that normally prevents toxicity from APAP. Fasting states are also known to disrupt detoxification of anti-TB drugs leading to change in the CYP system, predisposing to liver toxicity. ${ }^{71,72}$

Although recommendations for timing of medication administration or dose reduction based on circadian rhythm and resultant drug metabolism effects is a long way off, these results are nonetheless collectively intriguing. APAP is generally taken during times of illness, namely fever or pain, both of which are associated with fasting states. More prospective study in human based populations is needed.

\section{GUT MICROBIOME}

The role of the gut microbiome is also being explored for its potential as a means to protect against APAP-induced and antimicrobial DILI. ${ }^{73-75}$ Possamai and colleagues ${ }^{73}$ found that when given an intravenous dose of hepatotoxic APAP, the urinary ratio of APAPsulphate:glucuronide was significantly different when comparing the conventionally housed mice to the germ-free mice because the germ-free mice were found to have higher concentrations; however, interruption of Toll-like receptor 4 signaling was also protective, leading the investigators to conclude that the microbiome itself may play a role but not offer the complete explanation for the observed differences. Xue and colleagues ${ }^{74}$ recently published their experience with 3,4-dihydroxyphenylacetic acid, a microbiota-derived metabolite, and its protective role through nuclear factor-erythroid 2-related factor when exposed to toxic levels of APAP, also in mice. Using urinary bile acids as a surrogate for antimicrobial hepatoxicity, Bhowmik and colleagues ${ }^{75}$ demonstrated that gut microbiota may play a significant role in bile acid homeostasis and metabolism because germ-free mice had elevated levels of cholic acid and $a$-muricholic acid/ $\beta$-muricholic acid, which could predispose to hepatotoxicity in this sterile environment. The authors are unaware of any studies in human models investigated the role of the gut microbiome in predisposing or preventing DILI.

\section{ENVIRONMENTAL POLLUTION}

Exposure through an environment rich with pollution can place an individual at risk for hepatotoxicity and although the majority of liver injury is fairly benign with a modest elevation in liver-associated enzymes, ${ }^{76}$ rare instances of fatal hepatitis have been reported.

77 In a retrospective case-control study of 247 subjects, D'Andrea and Reddy ${ }^{76}$ found significantly elevated liver-associated enzymes in cases of oil spill clean-up workers exposed to potential toxins from the Gulf oil spill along the coast of Louisiana, perhaps directly attributable to benzenes and paraphenols. Exposure to organic pesticides, such as chlorpyrifos, endosulfan, and pyrethroids, ${ }^{78,79}$ often through wastewater exposure, ${ }^{80}$ has 
also been associated with hepatotoxicity. The importance of this cannot be understated, because a prospective study by Cecchi and colleagues ${ }^{81}$ of 97 women living in the rural Rio Negro province of Argentina found a predominant increase in alanine aminotransferase (ALT) values in the second trimester of pregnancy, with ALT greater than aspartate aminotransferase (AST). These laboratory abnormalities were not predictive, however, of worse maternal-fetal outcomes in the immediate postpartum period as measured by incidence rates of premature birth and miscarriage, and no cases of fatal hepatitis or nonfatal ALF were reported. ${ }^{81}$

\section{SUMMARY}

The role of environmental factors in predisposing a patient to both intrinsic DILI and iDILI remains a work in progress. Through the evolution of animal models, the complicated interaction between modifiable risk factors, such as tobacco smoking, excessive alcohol consumption, intestinal microbiome, environmental pollutants, and proinflammatory and/or hypercoagulable states, is only beginning to be understood. Although much research attention remains focused to identifying specific individual risk factors with genome-wide association studies, perhaps more attention should be focused on confirming the environmental observations from these animal models in human-based studies, both on observational and interventional levels. Understanding the environmental risk factors with a goal toward modification and prevention may be fruitful in light of medical treatment of both acute and chronic DILI limited by a lack of specific therapies and antidotes currently available; judicious use of a potentially hepatotoxic drug in a patient with underlying risk factors remains the mainstay of DILI management.

\section{Acknowledgments}

Research reported in this publication was supported by the National Institute of Diabetes and Digestive and Kidney Diseases of the National Institutes of Health under award number T32DK007769.

The content is solely the responsibility of the authors and does not necessarily represent the official views of the National Institutes of Health.

\section{REFERENCES}

1. Reuben A, Koch DG, Lee WM. Drug-induced acute liver failure: results of a U.S. multicenter, prospective study. Hepatology 2010;52(6):2065-76. [PubMed: 20949552]

2. Bjornsson E, Jerlstad P, Bergqvist A, et al. Fulminant drug-induced hepatic failure leading to death or liver transplantation in Sweden. Scand J Gastroenterol 2005; 40(9):1095-101. [PubMed: 16165719]

3. Chalasani N, Fontana RJ, Bonkovsky HL, et al. Causes, clinical features, and outcomes from a prospective study of drug-induced liver injury in the United States. Gastroenterology 2008;135(6): 1924-34.e1921-24.

4. Stine JG, Lewis JH. Drug-induced liver injury: a summary of recent advances. Expert Opin Drug Metab Toxicol 2011;7(7):875-90. [PubMed: 21510822]

5. Andrade RJ, Lucena MI, Fernandez MC, et al. Drug-induced liver injury: an analysis of 461 incidences submitted to the Spanish registry over a 10-year period. Gastroenterology 2005;129(2): 512-21. [PubMed: 16083708] 
6. Chalasani NP, Hayashi PH, Bonkovsky HL, et al. ACG Clinical Guideline: the diagnosis and management of idiosyncratic drug-induced liver injury. Am J Gastroenterol 2014;109(7):950-66 [quiz: 967]. [PubMed: 24935270]

7. Stine JG, Chalasani N. Chronic liver injury induced by drugs: a systematic review. Liver Int 2015;35(11):2343-53. [PubMed: 26346512]

8. Fontana RJ, Hayashi $\mathrm{PH}, \mathrm{Gu} \mathrm{J}$, et al. Idiosyncratic drug-induced liver injury is associated with substantial morbidity and mortality within 6 months from onset. Gastroenterology 2014;147(1):96108.e104. [PubMed: 24681128]

9. Devarbhavi H, Singh R, Patil M, et al. Outcome and determinants of mortality in 269 patients with combination anti-tuberculosis drug-induced liver injury. J Gastroenterol Hepatol 2013;28(1):161-7. [PubMed: 23020522]

10. Devarbhavi H, Dierkhising R, Kremers WK, et al. Single-center experience with drug-induced liver injury from India: causes, outcome, prognosis, and predictors of mortality. Am J Gastroenterol 2010;105(11):2396-404. [PubMed: 20648003]

11. Chalasani N, Bonkovsky HL, Fontana R, et al. Features and outcomes of 889 patients with druginduced liver injury: the DILIN prospective study. Gastroenterology 2015;48(7):1340-52.e7.

12. Zimmerman HJ. Hepatotoxicity: the adverse effects of drugs and other chemicals on the liver. 2nd edition Philadelphia: Lippincott-Williams \& Wilkins; 1999.

13. Kaplowitz N, DeLeve LD, editors. Drug-induced liver disease. 3rd edition London: Elsevier/ Academic Press; 2013 p. 746.

14. FDA drug stopping rules 2009 Available at: http://www.fda.gov/downloads/Drugs/.../Guidances/ UCM174090.pdf. Accessed April 11, 2016.

15. Lewis JH. The art and science of diagnosing and managing drug-induced liver injury in 2015 and beyond. Clin Gastroenterol Hepatol 2015;13(12):2173-89.e8. [PubMed: 26116527]

16. Lindquist M VigiBase, the WHO global ICSR database system: basic facts. Drug Inform J 2007;42:409-19.

17. Aagaard L, Strandell J, Melskens L, et al. Global patterns of adverse drug reactions over a decade: analyses of spontaneous reports to VigiBase. Drug Saf 2012;35(12):1171-82. [PubMed: 23072620]

18. Ampadu HH, Hoekman J, de Bruin ML, et al. Adverse drug reaction reporting in Africa and a comparison of individual case safety report characteristics between Africa and the rest of the world: analyses of spontaneous reports in vigiBase((R)). Drug Saf 2016;39(4):335-45. [PubMed: 26754924]

19. Suzuki A, Andrade RJ, Bjornsson E, et al. Drugs associated with hepatotoxicity and their reporting frequency of liver adverse events in VigiBase: unified list based on international collaborative work. Drug Saf 2010;33(6):503-22. [PubMed: 20486732]

20. Schmidt LE, Dalhoff K, Poulsen HE. Acute versus chronic alcohol consumption in acetaminopheninduced hepatotoxicity. Hepatology 2002;35(4):876-82. [PubMed: 11915034]

21. Maddrey WC. Hepatic effects of acetaminophen. Enhanced toxicity in alcoholics. J Clin Gastroenterol 1987;9(2):180-5. [PubMed: 3553308]

22. Zimmerman HJ, Maddrey WC. Acetaminophen (paracetamol) hepatotoxicity with regular intake of alcohol: analysis of instances of therapeutic misadventure. Hepatology 1995;22(3):767-73. [PubMed: 7657281]

23. Draganov P, Durrence H, Cox C, et al. Alcohol-acetaminophen syndrome. Even moderate social drinkers are at risk. Postgrad Med 2000;107(1):189-95.

24. Seeff LB, Cuccherini BA, Zimmerman HJ, et al. Acetaminophen hepatotoxicity in alcoholics. A therapeutic misadventure. Ann Intern Med 1986;104(3):399-404. [PubMed: 3511825]

25. Lauterburg BH, Davies S, Mitchell JR. Ethanol suppresses hepatic glutathione synthesis in rats in vivo. J Pharmacol Exp Ther 1984;230(1):7-11. [PubMed: 6747833]

26. Lauterburg BH, Velez ME. Glutathione deficiency in alcoholics: risk factor for paracetamol hepatotoxicity. Gut 1988;29(9):1153-7. [PubMed: 3197987]

27. Bray GP, Mowat C, Muir DF, et al. The effect of chronic alcohol intake on prognosis and outcome in paracetamol overdose. Hum Exp Toxicol 1991;10(6):435-8. [PubMed: 1687856] 
28. Gaude GS, Chaudhury A, Hattiholi J. Drug-induced hepatitis and the risk factors for liver injury in pulmonary tuberculosis patients. J Family Med Prim Care 2015; 4(2):238-43. [PubMed: 25949974]

29. Altomare E, Leo MA, Lieber CS. Interaction of acute ethanol administration with acetaminophen metabolism and toxicity in rats fed alcohol chronically. Alcohol Clin Exp Res 1984;8(4):405-8. [PubMed: 6385764]

30. Barve S, Kapoor R, Moghe A, et al. Focus on the liver: alcohol use, highly active antiretroviral therapy, and liver disease in HIV-infected patients. Alcohol Res Health 2010;33(3):229-36. [PubMed: 23584064]

31. Kumar S, Jin M, Ande A, et al. Alcohol consumption effect on antiretroviral therapy and HIV-1 pathogenesis: role of cytochrome P450 isozymes. Expert Opin Drug Metab Toxicol 2012;8(11): 1363-75. [PubMed: 22871069]

32. Stine JG, Intagliata N, Shah NL, et al. Hepatic decompensation likely attributable to simeprevir in patients with advanced cirrhosis. Dig Dis Sci 2015;60(4):1031-5. [PubMed: 25373453]

33. Pol S, Lamorthe B, Thi NT, et al. Retrospective analysis of the impact of HIV infection and alcohol use on chronic hepatitis C in a large cohort of drug users. J Hepatol 1998;28(6):945-50. [PubMed: 9672168]

34. Wit FW, Weverling GJ, Weel J, et al. Incidence of and risk factors for severe hepatotoxicity associated with antiretroviral combination therapy. J Infect Dis 2002; 186(1):23-31. [PubMed: 12089658]

35. Malatjalian DA, Ross JB, Williams CN, et al. Methotrexate hepatotoxicity in psoriatics: report of 104 patients from Nova Scotia, with analysis of risks from obesity, diabetes and alcohol consumption during long term follow-up. Can J Gastroenterol 1996;10(6):369-75. [PubMed: 9193771]

36. Whiting-O'Keefe QE, Fye KH, Sack KD. Methotrexate and histologic hepatic abnormalities: a meta-analysis. Am J Med 1991;90(6):711-6. [PubMed: 1828327]

37. Andrade RJ, Lucena MI, Kaplowitz N, et al. Outcome of acute idiosyncratic drug-induced liver injury: long-term follow-up in a hepatotoxicity registry. Hepatology 2006;44(6):1581-8. [PubMed: 17133470]

38. Zaverucha-do-Valle C, Monteiro SP, El-Jaick KB, et al. The role of cigarette smoking and liver enzymes polymorphisms in anti-tuberculosis drug-induced hepatotoxicity in Brazilian patients. Tuberculosis (Edinb) 2014;94(3):299-305. [PubMed: 24793319]

39. Czekaj P, Wiaderkiewicz A, Florek E, et al. Tobacco smoke-dependent changes in cytochrome $\mathrm{P} 450$ 1A1, 1A2, and 2E1 protein expressions in fetuses, newborns, pregnant rats, and human placenta. Arch Toxicol 2005;79(1):13-24. [PubMed: 15448981]

40. Hoofnagle JH. Drug-induced liver injury network (DILIN). Hepatology 2004;40(4): 773. [PubMed: 15382161]

41. Schmidt LE, Dalhoff K. The impact of current tobacco use on the outcome of paracetamol poisoning. Aliment Pharmacol Ther 2003;18(10):979-85. [PubMed: 14616163]

42. Wada T, Ueda M, Abe K, et al. Risk factor of liver disorders caused by flutamide-statistical analysis using multivariate logistic regression analysis. Hinyokika Kiyo 1999;45(8):521-6 [in Japanese]. [PubMed: 10500955]

43. Liguori MJ, Ditewig AC, Maddox JF, et al. Comparison of TNFalpha to lipopolysaccharide as an inflammagen to characterize the idiosyncratic hepatotoxicity potential of drugs: trovafloxacin as an example. Int J Mol Sci 2010;11(11): 4697-714. [PubMed: 21151465]

44. Shaw PJ, Ganey PE, Roth RA. Idiosyncratic drug-induced liver injury and the role of inflammatory stress with an emphasis on an animal model of trovafloxacin hepatotoxicity. Toxicol Sci 2010;118(1):7-18. [PubMed: 20538741]

45. Maddox JF, Amuzie CJ, Li M, et al. Bacterial- and viral-induced inflammation increases sensitivity to acetaminophen hepatotoxicity. J Toxicol Environ Health A 2010;73(1):58-73. [PubMed: 19953420]

46. Ganey PE, Luyendyk JP, Newport SW, et al. Role of the coagulation system in acetaminopheninduced hepatotoxicity in mice. Hepatology 2007;46(4):1177-86. [PubMed: 17654741] 
47. Liu J, Sendelbach LE, Parkinson A, et al. Endotoxin pretreatment protects against the hepatotoxicity of acetaminophen and carbon tetrachloride: role of cytochrome P450 suppression. Toxicology 2000;147(3):167-76. [PubMed: 10924799]

48. Labib R, Turkall R, Abdel-Rahman MS. Endotoxin potentiates the hepatotoxicity of cocaine in male mice. J Toxicol Environ Health A 2002;65(14):977-93. [PubMed: 12133232]

49. Lewis JH, Stine JG. Review article: prescribing medications in patients with cirrhosis - a practical guide. Aliment Pharmacol Ther 2013;37(12):1132-56. [PubMed: 23638982]

50. Lu J, Jones AD, Harkema JR, et al. Amiodarone exposure during modest inflammation induces idiosyncrasy-like liver injury in rats: role of tumor necrosis factor-alpha. Toxicol Sci 2012;125(1): 126-33. [PubMed: 21984482]

51. Zou W, Beggs KM, Sparkenbaugh EM, et al. Sulindac metabolism and synergy with tumor necrosis factor-alpha in a drug-inflammation interaction model of idiosyncratic liver injury. $\mathbf{J}$ Pharmacol Exp Ther 2009;331(1):114-21. [PubMed: 19638570]

52. Tukov FF, Luyendyk JP, Ganey PE, et al. The role of tumor necrosis factor alpha in lipopolysaccharide/ranitidine-induced inflammatory liver injury. Toxicol Sci 2007; 100(1):267-80. [PubMed: 17698507]

53. Cheng L, You Q, Yin H, et al. Effect of polyl: C cotreatment on halothane-induced liver injury in mice. Hepatology 2009;49(1):215-26. [PubMed: 19111017]

54. Shaw PJ, Fullerton AM, Scott MA, et al. The role of the hemostatic system in murine liver injury induced by coexposure to lipopolysaccharide and trovafloxacin, a drug with idiosyncratic liability. Toxicol Appl Pharmacol 2009;236(3):293-300. [PubMed: 19367693]

55. Verrijken A, Francque S, Mertens I, et al. Prothrombotic factors in histologically proven NAFLD and NASH. Hepatology 2014;59(1):121-9. [PubMed: 24375485]

56. Luyendyk JP, Maddox JF, Green CD, et al. Role of hepatic fibrin in idiosyncrasylike liver injury from lipopolysaccharide-ranitidine coexposure in rats. Hepatology 2004;40(6):1342-51. [PubMed: 15565632]

57. Stravitz RT, Bowling R, Bradford RL, et al. Role of procoagulant microparticles in mediating complications and outcome of acute liver injury/acute liver failure. Hepatology 2013;58(1):30413. [PubMed: 23389887]

58. Souayed N, Chennoufi M, Boughattas F, et al. Circadian variation in murine hepatotoxicity to the antituberculosis agent <<lsoniazide〉>. Chronobiol Int 2015; 32(9):1201-10. [PubMed: 26479844]

59. Levi F, Schibler U. Circadian rhythms: mechanisms and therapeutic implications. Annu Rev Pharmacol Toxicol 2007;47:593-628. [PubMed: 17209800]

60. DeBruyne JP, Weaver DR, Dallmann R. The hepatic circadian clock modulates xenobiotic metabolism in mice. J Biol Rhythms 2014;29(4):277-87. [PubMed: 25238856]

61. Johnson BP, Walisser JA, Liu Y, et al. Hepatocyte circadian clock controls acetaminophen bioactivation through NADPH-cytochrome P450 oxidoreductase. Proc Natl Acad Sci U S A 2014;111(52):18757-62. [PubMed: 25512522]

62. Wang T, Yang P, Zhan Y, et al. Deletion of circadian gene Per1 alleviates acute ethanol-induced hepatotoxicity in mice. Toxicology 2013;314(2-3):193-201. [PubMed: 24144995]

63. Xu YQ, Zhang D, Jin T, et al. Diurnal variation of hepatic antioxidant gene expression in mice. PLoS One 2012;7(8):e44237. [PubMed: 22952936]

64. Kakan X, Chen P, Zhang J. Clock gene mPer2 functions in diurnal variation of acetaminophen induced hepatotoxicity in mice. Exp Toxicol Pathol 2011;63(6): 581-5. [PubMed: 20472413]

65. Boorman GA, Blackshear PE, Parker JS, et al. Hepatic gene expression changes throughout the day in the Fischer rat: implications for toxicogenomic experiments. Toxicol Sci 2005;86(1):185-93. [PubMed: 15814895]

66. Bruckner JV, Ramanathan R, Lee KM, et al. Mechanisms of circadian rhythmicity of carbon tetrachloride hepatotoxicity. J Pharmacol Exp Ther 2002;300(1): 273-81. [PubMed: 11752126]

67. Ngong JM, Waring RH. Circadian rhythms of paracetamol metabolism in healthy subjects; a preliminary report. Drug Metabol Drug Interact 1994; 11(4):317-30. [PubMed: 12369755]

68. Schnell RC, Bozigian HP, Davies MH, et al. Circadian rhythm in acetaminophen toxicity: role of nonprotein sulfhydryls. Toxicol Appl Pharmacol 1983;71(3): 353-61. [PubMed: 6658786] 
69. Howell SR, Klaassen C. Circadian variation of hepatic UDP-glucuronic acid and the glucuronidation of xenobiotics in mice. Toxicol Lett 1991;57(1):73-9. [PubMed: 2048163]

70. Martensson J The effect of fasting on leukocyte and plasma glutathione and sulfur amino acid concentrations. Metabolism 1986;35(2):118-21. [PubMed: 3945186]

71. Walter-Sack I, Klotz U. Influence of diet and nutritional status on drug metabolism. Clin Pharmacokinet 1996;31(1):47-64. [PubMed: 8827399]

72. Buchanan N, Eyberg C, Davis MD. Isoniazid pharmacokinetics in kwashiorkor. S Afr Med J 1979;56(8):299-300. [PubMed: 550491]

73. Possamai LA, McPhail MJ, Khamri W, et al. The role of intestinal microbiota in murine models of acetaminophen-induced hepatotoxicity. Liver Int 2015;35(3): 764-73. [PubMed: 25244648]

74. Xue H, Xie W, Jiang Z, et al. 3,4-Dihydroxyphenylacetic acid, a microbiota-derived metabolite of quercetin, attenuates acetaminophen (APAP)-induced liver injury through activation of Nrf-2. Xenobiotica 2016;46(10):1-9. [PubMed: 26068521]

75. Bhowmik SK, An JH, Lee SH, et al. Alteration of bile acid metabolism in pseudo germ-free rats [corrected]. Arch Pharm Res 2012;35(11):1969-77. [PubMed: 23212639]

76. D'Andrea MA, Reddy GK. Health consequences among subjects involved in Gulf oil spill clean-up activities. Am J Med 2013;126(11):966-74. [PubMed: 24050487]

77. Payan-Renteria R, Garibay-Chavez G, Rangel-Ascencio R, et al. Effect of chronic pesticide exposure in farm workers of a Mexico community. Arch Environ Occup Health 2012;67(1):22-30. [PubMed: 22315932]

78. Hodgson E, Rose RL. Organophosphorus chemicals: potent inhibitors of the human metabolism of steroid hormones and xenobiotics. Drug Metab Rev 2006; 38(1-2):149-62. [PubMed: 16684654]

79. Hodgson E, Rose RL. Human metabolic interactions of environmental chemicals. J Biochem Mol Toxicol 2007;21(4):182-6. [PubMed: 17936932]

80. Gao H, Liu Y, Guan W, et al. Hepatotoxicity and nephrotoxicity of organic contaminants in wastewater-irrigated soil. Environ Sci Pollut Res Int 2015;22(5): 3748-55. [PubMed: 25263415]

81. Cecchi A, Rovedatti MG, Sabino G, et al. Environmental exposure to organophosphate pesticides: assessment of endocrine disruption and hepatotoxicity in pregnant women. Ecotoxicol Environ Saf 2012;80:280-7. [PubMed: 22494479] 


\begin{tabular}{|c|c|}
\hline Box 1 & Environmental risk factors for drug-induced liver injury \\
\hline & $\begin{array}{l}\text { Intrinsic } \\
\text { Circadian rhythm } \\
\text { Hepatic clock } \\
\text { Infection } \\
\text { Inflammation } \\
\text { Intestinal microbiome } \\
\text { Extrinsic } \\
\text { Alcohol consumption } \\
\text { Regional geographic variation } \\
\text { Smoking } \\
\text { Socioeconomic status } \\
\text { Environmental pollution }\end{array}$ \\
\hline$\bullet$ & $\begin{array}{l}\text { KEY POINTS } \\
\text { In general, human data on the environment and drug-induced liver injury } \\
\text { (DILI) are sparse and the majority of understanding is derived from animal } \\
\text { studies of both intrinsic and idiosyncratic injury. } \\
\text { Smoking can induce cytochrome P450 (CYP) enzymes but this does not } \\
\text { necessarily translate into DILI. } \\
\text { Alcohol consumption is a clear risk factor for hepatotoxicity from } \\
\text { acetaminophen (APAP) and may predispose to injury from antituberculosis } \\
\text { (anti-TB) medications but large international registries have not found an } \\
\text { association between excessive alcohol consumption and DILI in general. } \\
\text { Understanding of the role of infection, proinflammatory states, the hepatic } \\
\text { clock, environmental pollutants, and the microbiome in predisposing an } \\
\text { individual to DILI is still evolving. }\end{array}$ \\
\hline
\end{tabular}

